\title{
Concentration of hepatic vitamins $A$ and $E$ in rats exposed to chlorpyrifos and/or enrofloxacin
}

\author{
A. Spodniewska, D. Barski \\ Department of Pharmacology and Toxicology, Faculty of Veterinary Medicine, \\ University of Warmia and Mazury in Olsztyn, Oczapowskiego 14, 10-719 Olsztyn, Poland
}

\begin{abstract}
The aim of the study was to determine the level of antioxidant vitamins $\mathrm{A}$ and $\mathrm{E}$ in the liver of rats exposed to chlorpyrifos and/or enrofloxacin. Chlorpyrifos (Group I) was administered at a dose of $0.04 \mathrm{LD}_{50}(6 \mathrm{mg} / \mathrm{kg}$ b.w.) for 28 days, and enrofloxacin (Group II) at a dose of $5 \mathrm{mg} / \mathrm{kg}$ b.w. for 5 consecutive days. The animals of group III were given both of the mentioned above compounds at the same manner as groups I and II, but enrofloxacin was applied to rats for the last 5 days of chlorpyrifos exposure (i.e. on day 24, 25, 26, 27 and 28). Chlorpyrifos and enrofloxacin were administered to rats intragastrically via a gastric tube. The quantitative determination of vitamins was made by the HPLC method. The results of this study indicated a reduction in the hepatic concentrations of vitamins $\mathrm{A}$ and $\mathrm{E}$, compared to the control, which sustained for the entire period of the experiment. The four-week administration of chlorpyrifos to rats resulted in a significant decrease of vitamins in the initial period of the experiment, i.e. up to 24 hours after exposure. For vitamin A the maximum drop was observed after 24 hours (19.24\%) and for vitamin E after 6 hours (23.19\%). Enrofloxacin caused a slight (3-9\%) reduction in the level of the analysed vitamins. In the chlorpyrifos-enrofloxacin co-exposure group reduced vitamins $\mathrm{A}$ and $\mathrm{E}$ levels were also noted, but changes in this group were less pronounced in comparison to the animals intoxicated with chlorpyrifos only. The decrease in the antioxidant vitamin levels, particularly noticeable in the chlorpyrifos- and the chlorpyrifos combined with enrofloxacin-treated groups, may result not only from the increase in the concentration of free radicals, but also from the intensification of the secondary stages of lipid peroxidation.
\end{abstract}

Key words: chlorpyrifos, enrofloxacin, vitamin A, vitamin E, rats

\section{Introduction}

Environmental pollution plays a crucial role in the occurrence of health problems affecting animals and human beings. Investigations which have been conducted in recent years indicate the need for studies estimating the potential harmful effects of substances of high biological activity, such as pesticides and medicines. A great deal of emphasis has been placed on evaluating the potential harmfulness of co-intoxication with these compounds (Liu et al. 2006, Wielgomas and Krechniak 2007).

Correspondence to: A. Spodniewska, e-mail: anspod@uwm.edu.pl 
Environmental pollution by pesticides is a major environmental concern due to their extensive use in agriculture and in public health programmes (Casida and Quistad 2004, Aktar et al. 2009). Organophosphorus (OP) compounds constitute the largest and the most diverse group of insecticides. Chlorpyrifos (O,O-diethyl O-3,5,6-trichloropyridin-2-yl phosphorothioate) is a widely used OP insecticide for agricultural and domestic applications in the whole world (Lemus and Abdelghani 2000). Similar to other phosphorothioate pesticides, chlorpyrifos acts primarily by inhibiting neuronal acetylcholinesterase (AChE) activity, thereby interfering with normal cholinergic nerve transmissions (Nigg and Knaak 2000). Recent studies have indicated that chlorpyrifos affects several biochemical pathways that are independent of the modulation of the AChE enzyme. One such mechanism associated with both acute and chronic poisoning is oxidative stress. Several studies point to the generation of ROS as a secondary molecular mechanism of the toxicity of some pesticides (Akhgari et al. 2003, Bebe and Panemanogalore 2003).

Another group of compounds, which are more and more often used in medicine, comprise fluoroquinolones. They are currently one of the main classes of antmicrobial agents used worldwide. The clinical use of these drugs is not restricted to human medicine, but is also widely applied in the treatment and prevention of veterinary diseases (Ihrke et al. 1999, Gotfried and Grossman 2010). Enrofloxacin belongs to the group of synthetic 6-fluoroquinolones and it is marketed specifically for use in veterinary medicine (Martinez et al. 2006). It is effective against some Gram-positive and Gram-negative bacteria, mycoplasmas and some rickettsial organisms (Vancutsem et al. 1990). The mechanism of action of enrofloxacin consists of the inhibition of bacterial DNA gyrase, which plays a basic role in the process of DNA replication, leading to the inhibition of the synthesis of bacterial proteins (Wang et al. 2010). Even though during therapy temporary gastrointestinal as well as biochemical and hematological disorders are observed, enrofloxacin is classed as a relatively safe drug, similarly to the whole group of fluoroquinolones (Tras et al. 2001, Stahlmann 2002). Investigations conducted in recent years suggest that one negative effect of fluoroquinolones administration could be the generation of reactive oxygen species (ROS) (Ibrahim and Yarsan 2011). Side effects such as phototoxiticity and cartilage damage may be related to the production of ROS (Pouzaud et al. 2006, Rampal et al. 2008).

The toxicity of many xenobiotics is associated with the production of free radicals, which are not only toxic themselves, but are also implicated in the pathophysiology of many diseases. They may produce oxidative stress by generating free radicals and inducing or altering enzymatic and non-enzymatic antioxidant systems (Hybertson et al. 2011). To counteract the toxicity of active oxygen species the cells are equipped with a highly efficient antioxidative defence system, including both enzymatic constituents (SOD, CAT, GPx, GR) as well as low-molecular compounds (e.g. glutathione, ascorbic acid, carotenoids and tocopherols) (Sies 1997, Irshad and Chaudhri 2002). Each of these antioxidants has specific activities, and they often work synergistically to enhance the overall antioxidant capacity of the body.

Although it is known that both organophosphorus insecticides and fluoroquinolones may induce oxidative stress, the data regarding their influence on the level of antioxidant vitamins are very limited. It is also worth emphasizing that fluoroquinolones are widely and increasingly used in veterinary medicine, with enrofloxacin being the most common, and the use of chlorpyrifos is still increasing. Recently attention has been drawn not only to the adverse effects of individual xenobiotics, but also to their interactions with one another, so studies of such interactions are one of the important areas of toxicology research. Therefore, looking at the widespread applications of both enrofloxacin and chlorpyrifos, the aim of this study was to determine the concentrations of vitamins $\mathrm{A}$ and $\mathrm{E}$ in the liver of rats exposed to chlorpyrifos and enrofloxacin (given alone and in combination), and to assess the time interval for the persistence of changes following the discontinuation of the administration of the studied compounds. To the best of our knowledge no similar studies have been conducted before.

\section{Materials and Methods}

Chlorpyrifos (purity min. 99.8\%) was obtained from the Institute of Industrial Organic Chemistry (Warszawa, Poland). Commercial formulation of enrofloxacin (ENFLOCYNA ${ }^{\circledR}$ SOL) was purchased from Biowet Puławy Ltd. (Puławy, Poland), and contained $50 \mathrm{mg} / \mathrm{mL}$ of the active substance. All the other chemical and reagents used were of analytical grade or better and commercially available.

Adult male rats of Wistar strain $(n=120)$, weighing $170 \pm 10 \mathrm{~g}$, were used for the study. The animals were kept under standard experimental conditions with ad libitum food and water.

The rats were randomly divided into three experimental groups and one control group of 30 animals each. Group I was administered chlorpyrifos in a sunflower oil solution at a dose of $6 \mathrm{mg} / \mathrm{kg}$ b.w. (0.04 $\mathrm{LD}_{50}$ ) daily for 28 days. Group II was given with en- 
rofloxacin (ENFLOCYNA ${ }^{\circledR}$ SOL), in an aqueous solution, at a therapeutic dose of $5 \mathrm{mg} / \mathrm{kg}$ b.w.per day, for five subsequent days. The animals of group III were given both of the mentioned above compounds at the same manner as groups I and II, but enrofloxacin was applied to rats for the last 5 days of chlorpyrifos exposure (i.e. on day 24, 25, 26, 27 and 28). The remaining group was untreated and used as the control.

The experimental design and procedures has been approved by the Local Ethics Committee for Animal Experiments at the University of Warmia and Mazury in Olsztyn, Poland.

Experimental material from 6 rats randomly selected from each group was obtained after 3, 6, and 24 hours, and 3 and 7 days following the last applied dose of the compounds under study. The livers were immediately washed in ice-cold $0.9 \% \mathrm{NaCl}$, weighed and frozen at $-80^{\circ} \mathrm{C}$ for a further analysis of vitamins $\mathrm{A}$ and $\mathrm{E}$.

Chromatographic quantitation of retinol and $\alpha$-tocopherol levels in the liver was performed in a reversed-phase liquid chromatography (Shimadzu HPLC system: pumps LC-20AD, degasser DGU-20A 3 , column oven CTO-10AS). The analytical column was a Nucleosil C18 $(250 \times 4.6 \mathrm{~mm})$ with a particle size of $5 \mu \mathrm{m}$, supplied by Mecherey-Nagel. The mobile phase was methanol: $\mathrm{H}_{2} \mathrm{O}(95: 5 \mathrm{v} / \mathrm{v})$, flow rate $1 \mathrm{~mL} / \mathrm{min}$, loop $20 \mu$ l. The liver concentrations of retinol were determined using detector UV-vis - 326 $\mathrm{nm}$ and $\alpha$-tocopherol using detector RF-20A FLUORESCENCE: $\mathrm{E}_{\mathrm{x}} 293 \mathrm{~nm}$ and $\mathrm{E}_{\mathrm{m}} 326 \mathrm{~nm}$. Concentrations of vitamin $\mathrm{A}$ and $\mathrm{E}$ were calculated by comparison to external standards: $\alpha$-Tocopherol (DL-all-rac $\alpha$-tocopherol) and Retionol Vitamin A - alcohol (Sigma-Aldrich). The data was expressed as $\mu \mathrm{g} / \mathrm{g}$ of liver tissue.

All data were expressed as a mean \pm SD (standard deviation) and analyzed using one-way analysis of variance (ANOVA) followed by Newman-Keuls t-test as a post hoc test for a comparison between the groups. The differences were considered significant at $\mathrm{p}<0.05$. Statistical calculations were performed using Statistica 10 PL software (StatSoft, Poland).

\section{Results}

The results of hepatic vitamins A and E concentrations in particular groups and time intervals are presented in Tables 1-2.

Exposure of rats to chlorpyrifos and enrofloxacin, administered either alone or in combination, had no effect on the animals' behaviour or body weight.

The concentration of vitamins $\mathrm{A}$ and $\mathrm{E}$ in the liver was decreased in comparison with the control in all experimental groups throughout the experiment and did not reach the control values until the completion of the study, i.e. up to the 7th day.

In the group of rats exposed to enrofloxacin only a slight decrease (3-9\%) in the content of vitamin $\mathrm{A}$ and $\mathrm{E}$ was observed compared to the control group. However, the level of these vitamins was higher than that found in the chlorpyrifos- and the chlorpyrifos combined with enrofloxacin-treated groups

The content of vitamins $\mathrm{A}$ and $\mathrm{E}$ in subacute intoxication with chlorpyrifos was significantly $(\mathrm{p}<0.05)$ reduced in the initial period of the experiment. For vitamin A the maximum drop was observed after 24 hours (19.2\%), and for vitamin E after 6 hours (23.2\%), compared to the control group. The decrease in the level of vitamin $\mathrm{E}$ in this group was greater than that of vitamin A.

Combined application of chlorpyrifos and enrofloxacin to rats resulted in a significant decrease in vitamin A content, compared to controls, after 24 hours $(17.1 \%)$. Vitamin E levels decreased gradually up to 24 hours, and were, respectively $17.3 \%, 15.2 \%$ and $14.8 \%$ after 3, 6 and 24 hours. In this group a slightly reduced level of these vitamins was observed in comparison with the chlorpyrifos group, but this decrease was greater compared to the enrofloxacin group.

\section{Discussion}

Among numerous chemical compounds posing a health hazard to animals and humans, substances with high biological activity, such as pesticides and drugs, are particularly important. However, no special attention has been paid to the simultaneous administration of agrochemicals and medicaments, such as those investigated in this work.

Cells have several ways to alleviate the effects of oxidative stress, either by repairing the damage or by directly reducing the prooxidative state via enzymatic and non-enzymatic antioxidants which have been shown to scavenge free radical and ROS (Kulikowska-Karpińska and Moniuszko-Jakoniuk 2004, Bando et al. 2005). Most studies involving antioxidants and their role in combating cellular oxidative stress in animals have focused on the alteration in various endogenous enzymatic and non-enzymatic components of the antioxidant defence system (such as SOD, CAT, GPx, GSH). In contrast, only a few studies have examined exogenous antioxidants such as retinoids and vitamin E (Rodriguez-Estival et al. 2011, Defo et al. 2014).

Antioxidant vitamins can prevent the uncontrolled 
Table 1. Concentration of vitamin A in the liver of rats exposed to chlorpyrifos, enrofloxacin and their combination ( $\mu \mathrm{g} / \mathrm{g}$ of fresh tissue).

\begin{tabular}{ccccc}
\hline \multirow{2}{*}{$\begin{array}{c}\text { Time after } \\
\text { intoxication }\end{array}$} & $\begin{array}{c}\text { Control } \\
(\mathrm{n}=6)\end{array}$ & $\begin{array}{c}\text { Chlorpyrifos } \\
(\mathrm{n}=6)\end{array}$ & $\begin{array}{c}\text { Enrofloxacin } \\
(\mathrm{n}=6)\end{array}$ & $\begin{array}{c}\text { Chlorpyrifos and } \\
\text { Enrofloxacin }(\mathrm{n}=6)\end{array}$ \\
\hline $3 \mathrm{~h}$ & $109.92 \pm 2.06^{\mathrm{a}}$ & $94.99 \pm 5.68^{\mathrm{b}}$ & $100.78 \pm 0.78^{\mathrm{ab}}$ & $97.30 \pm 4.84^{\mathrm{ab}}$ \\
\hline $6 \mathrm{~h}$ & $114.19 \pm 6.71^{\mathrm{a}}$ & $96.58 \pm 5.69^{\mathrm{b}}$ & $105.23 \pm 4.48^{\mathrm{ab}}$ & $101.65 \pm 5.89^{\mathrm{ab}}$ \\
\hline $24 \mathrm{~h}$ & $117.85 \pm 3.18^{\mathrm{a}}$ & $95.21 \pm 6.19^{\mathrm{b}}$ & $108.01 \pm 6.92^{\mathrm{a}}$ & $97.66 \pm 2.17^{\mathrm{b}}$ \\
\hline $3 \mathrm{~d}$ & $110.42 \pm 3.72^{\mathrm{ab}}$ & $96.56 \pm 8.72^{\mathrm{a}}$ & $104.66 \pm 4.59^{\mathrm{ab}}$ & $108.34 \pm 4.29^{\mathrm{b}}$ \\
\hline $7 \mathrm{~d}$ & $114.28 \pm 2.26^{\mathrm{a}}$ & $108,60 \pm 6.23^{\mathrm{a}}$ & $110.69 \pm 6.26^{\mathrm{a}}$ & $114.82 \pm 4.62^{\mathrm{a}}$ \\
\hline
\end{tabular}

values expressed as means $\pm \mathrm{SD}$; means marked by the same letter within the rows are not significantly different

Table 2. Concentration of vitamin $\mathrm{E}$ in the liver of rats exposed to chlorpyrifos, enrofloxacin and their combination $(\mu \mathrm{g} / \mathrm{g}$ of fresh tissue).

\begin{tabular}{ccccc}
\hline \multirow{2}{*}{$\begin{array}{c}\text { Time after } \\
\text { intoxication }\end{array}$} & $\begin{array}{c}\text { Control } \\
(\mathrm{n}=6)\end{array}$ & $\begin{array}{c}\text { Chlorpyrifos } \\
(\mathrm{n}=6)\end{array}$ & $\begin{array}{c}\text { Enrofloxacin } \\
(\mathrm{n}=6)\end{array}$ & $\begin{array}{c}\text { Chlorpyrifos and } \\
\text { Enrofloxacin }(\mathrm{n}=6)\end{array}$ \\
\hline $3 \mathrm{~h}$ & $17.61 \pm 2.06^{\mathrm{a}}$ & $14.11 \pm 2.85^{\mathrm{b}}$ & $16.78 \pm 0.78^{\mathrm{a}}$ & $14.57 \pm 1.84^{\mathrm{b}}$ \\
\hline $6 \mathrm{~h}$ & $16.19 \pm 0.82^{\mathrm{a}}$ & $12.43 \pm 1.54^{\mathrm{b}}$ & $14.75 \pm 1.45^{\mathrm{ac}}$ & $13.74 \pm 2.53^{\mathrm{bc}}$ \\
\hline $24 \mathrm{~h}$ & $15.60 \pm 0.9^{\mathrm{a}}$ & $12.47 \pm 1.36^{\mathrm{b}}$ & $14.32 \pm 1.05^{\mathrm{ac}}$ & $13.30 \pm 1.12^{\mathrm{bc}}$ \\
\hline $3 \mathrm{~d}$ & $16.15 \pm 2.12^{\mathrm{a}}$ & $13.84 \pm 1.97^{\mathrm{b}}$ & $14.88 \pm 1.84^{\mathrm{ab}}$ & $14.68 \pm 1.88^{\mathrm{ab}}$ \\
\hline $7 \mathrm{~d}$ & $15.40 \pm 2.69^{\mathrm{a}}$ & $13.66 \pm 1.36^{\mathrm{a}}$ & $14.72 \pm 2.32^{\mathrm{a}}$ & $14.01 \pm 1.47^{\mathrm{a}}$ \\
\hline
\end{tabular}

values expressed as means $\pm \mathrm{SD}$; means marked by the same letter within the rows are not significantly different.

formation of free radicals, and inactivate oxygen species or inhibit their reaction with biological structures. Vitamin A (retinol) and vitamin E ( $\alpha$-tocopherol) are low molecular compounds that exhibit high biological activity against oxidants and free radicals (Sies and Stahl 1995). They are absorbed by blood via the lymphatic system, and reach the liver and fatty acid tissues where they are stored. Despite low concentrations, these vitamins prevent the accumulation of free radicals through either neutralising them or increasing the defensive capabilities of other endogenous antioxidants. Lipophilic vitamin A plays an important role in the functioning of the cell and the entire organism. It can react with peroxide radicals, and so interrupts the chain reaction of lipid peroxidation forming hydroperoxides. Vitamin A is also capable of reacting directly with ROS (Edge et al. 1997).

Vitamin E is a major lipid-soluble antioxidant present in the membranes of cells and cellular organelles, where it plays an important role in the suppression of lipid oxidation (Traber and Atkinson 2007). It reacts more rapidly than polyunsaturated fatty acids with peroxyl radicals, and hence breaks the chain reaction of lipid peroxidation. In addition to its antioxidant role, vitamin E might also have a struc- tural role in stabilizing membranes (Kamal-Eldin and Appelqvist 1996).

Organophosphate insecticides have been extensively studied for their toxic potential (Sultatos 1994, Eddleston 2012). However, pesticide-induced oxidative stress has been the focus of toxicological research for over a decade and many investigations have been focused on the alteration of particular components of the antioxidant system (Giordano et al. 2007, Ben Amara et al. 2014). The number of studies concerned with the impact of insecticides on the level of antioxidant vitamins is limited.

Results of the present study show that after 28-days intoxication with chlorpyrifos, the concentration of vitamins $\mathrm{A}$ and $\mathrm{E}$ decreased in comparison to the control group for the entire period of the experiment. A significant $(\mathrm{p}<0.05)$ drop in the content of these vitamins was observed in the initial period of the experiment, i.e. up to 24 hours. Similar results were also obtained by other authors. The decrease in the vitamin A level was observed in the serum of rats following a single intoxication with fenthion (Buyukokuroglu et al. 2008, Cemek et al. 2010). Ben Amara et al. (2012) reported that subacute exposure to dimethoate was characterized by the depletion of 
vitamin $\mathrm{E}$ in rat erythrocytes. Other types of pesticides can also cause a reduction in vitamin A content. Fernie et al. (2005) recorded that hepatic retinol concentrations were nearly $50 \%$ reduced in PBDEs (polybrominated diphenyl ethers)-exposed American kestrels. Our results indicate that the reduction in the level of antioxidant vitamins may be attributed to the prooxidative properties of chlorpyrifos. Potentially, chlorpyrifos exposure began to exceed the capabilities of the antioxidant involving vitamins.

The majority of publications on fluoroquinolones mainly focus on the efficacy of its therapeutic activity (Suojala 2010, Zhang et al. 2012) and the data on its effects on antioxidant status are still limited (Albesa et al. 2004, Becerra et al. 2004). In our study, the exposure of rats to enrofloxacin caused an insignificant decrease in hepatic vitamins $A$ and $E$ levels. Because there is no available data investigating the effect of fluoroquinilones on these parameters, it is difficult to compare the results with the findings of other authors. However, the observed slight decline in the analysed vitamins may be the result of the prooxidative action of enrofloxacin, and may indicate impairment of antioxidant mechanisms.

In recent years there has been an increasing number of data concerning the interaction of organophosphate insecticides with different compounds and their impact on the oxidative processes. However, the majority of studies discuss the protective effect of vitamins or microelements with exposure to organophosphate insecticides (Verma et al. 2007, Abdallach et al. 2011) or the influence of mixtures of pesticides (El-Demerdash 2011, Ojha and Srivastava 2012). To the best of our knowledge a very limited number of investigations refer to the consequences caused by the co-administration of pesticides and medicaments (Gelal et al. 2001, Babu et al. 2006, Suarez et al. 2014), and only individual ones focus on oxidative stress (Barski and Spodniewska 2012, Spodniewska et al. 2014).

In the current study, in the group with combined intoxication with chlorpyrifos and enrofloxacin, the levels of vitamins $\mathrm{A}$ and $\mathrm{E}$ were reduced throughout the experiment. However, no synergistic effect of both compounds was found, as the observed changes of the vitamin levels were less pronounced as compared to the chlorpyrifos-treated rats. In the available literature, a few papers concerning the content of lipophilic antioxidant vitamins in the tissues of animals exposed to pesticide mixtures were found. In rats and mice, exposure to PBDEs and PCBs mixtures have been shown to cause a reduction in hepatic retinol level (Hallgren et al. 2001). Twaroski et al. (2001) reported that various PCBs congeners treatments of rats led to a decrease in hepatic $\alpha$-tocopherol and an increase in $\alpha$-tocopheryl quinine (an oxidized form of $\alpha$-tocopherol). In research on rats treated with pesticides (dimethoate, zineb and glyphosate), alone and in combination, Astiz et al. (2009) showed a decline of $\alpha$-tocopherol in the liver and brain (30-60\%), particularly noticeable in the case of mixed intoxication. On the other hand, the non-dioxin-like PCBs did not significantly alter the retinol content, indicating that in the case of exposure to these PCBs at environmental levels, no effects, or only marginal effects, can be expected.

In our study, the largest decrease in the content of vitamins $\mathrm{A}$ and $\mathrm{E}$ in the liver of rats was noted in the chlorpyrifos-treated group, as well as in the group with combined intoxication with chlorpyrifos and enrofloxacin. These changes were particularly noticeable in the initial period of the study, i.e. up to the 24 th hour following exposure. This may indicate that during this period both increased generation of free radicals and intensified oxidative stress occurred.

The mechanism of the action of the antioxidant compound follows more than one type to reduce the impact of the oxidative stress induced in living organisms. The reduction in the level of vitamins $\mathrm{A}$ and $\mathrm{E}$ may be explained by the intensified utilisation of these vitamins in protection against oxidative damage to tissues. Vitamin E effectively reacts with organic lipid radicals produced in the process of lipid peroxidation (Liebler 1993). Therefore, it can be assumed that the decrease in vitamin $\mathrm{E}$ concentration in the liver after chlorpyrifos and enrofloxacin exposure is due to the interaction of this vitamin with radicals generated during lipid peroxidation. A decrease in the antioxidant vitamin level may also result from the intensification of the secondary stages of lipid peroxidation. Chow et al. (1999) demonstrated that a decrease in the content of vitamin $\mathrm{E}$ leads to a marked increase in the production of $\mathrm{H}_{2} \mathrm{O}_{2}$ in both the mitochondria of skeletal muscles and the mitochondria of the liver.

It should also be remembered that the capacity of antioxidants in vivo is determined by many factors which should be taken into consideration in its assessment. One such factor is bioavailability. The antioxidants should be absorbed, transported, distributed and retained properly in the biological fluids, cells and tissues. Intestinal absorption of fat-soluble vitamins is dependent on the digestion volume and absorption rate of fat. Thus, any perturbation of lipid absorption would result in a similar perturbation in vitamin absorption. It has been suggested that the compounds used in our study might interfere with nutrient absorption and also with the levels of antioxidants present in feed. Lee et al. (2008) suggested that vitamin A might act as an antioxidant, and it is possible that it is not transformed and accumulated in the liver as 
retinyl esters because it is rapidly consumed by scavenging free radicals. Another possibility is that the biosynthesis of retinyl esters is inhibited under conditions of oxidative stress, and this may have negative consequences for overall vitamin A homeostasis. The diminished content of vitamin A may also be caused by the loss or transformation of the storage stellate cells in the liver.

Another reason for the decrease in the level of the analysed vitamins could be the inflammatory processes resulting from the exposure to the compounds used in the experiment. As a result of the ROS generation during the inflammation, chemical changes occur within antioxidant molecules which lead to their inactivation. This is confirmed by a study concerning the level of vitamin $\mathrm{E}$ in inflamed intestinal mucosa, which demonstrated the level of $\alpha$-tocopherol being two times lower than in the control group (Hengstermann et al. 2008).

It seems interesting that in rats exposed simultaneously to chlorpyrifos and enrofloxacin the decrease in the levels of both vitamin $\mathrm{A}$ and $\mathrm{E}$ was smaller than in the group of rats intoxicated exclusively with chlorpyrifos. It is known that the hepatic metabolism of xenobiotics with the participation of cytochrome P450 may also be a source of disorders in the free radical metabolism.

In mammals, the cytochrome $\mathrm{P} 450$ isoforms (CYPs) involved in the metabolism of xenobiotics belong mostly to the families CYP1-CYP3. The same CYPs are often involved in the biotransformation of such compounds as pesticides and commonly used drugs (e.g. fluoroquinolones) (Anzenbacher and Anzenbacherova 2001, Mutch and Wiliams 2006). The most frequent consequence of that interaction is an increase in the toxicity of substances, the metabolism of which was inhibited. No such phenomenon was observed in our study. Similarly to our research, the study of Wiaderkiewicz et al. (2006) showed that the stimulatory effect of dimethoate on the content of cytochrome $\mathrm{P} 450$ was abolished in rats simultaneously administered with pyrantel.

The present study indicates that both chlorpyrifos and enrofloxacin and their combination reduce the concentrations of vitamins $\mathrm{A}$ and $\mathrm{E}$ in the liver of rats, indicating the occurrence of oxidative stress. The levels of these vitamins did not reach the control values until the completion of the study, i.e. up to the 7 th day following the discontinuation of the administration of the compounds used in the experiment. The decrease in the antioxidant vitamin levels was particularly noticeable in the groups exposed to chlorpyrifos and the combination of chlorpyrifos and enrofloxacin, but changes to vitamin levels were less pronounced in the latter group. Even though enrofloxacin is con- sidered to be a relatively safe medicament for animals, the conducted studies indicate that it may induce insignificant oxidative stress.

\section{References}

Abdallah FB, Gargouri B, Bejaoui H, Lassoued S, Ammar-Keskes L (2011) Dimethoate-induced oxidative stress in human erythrocytes and the protective effect of vitamins $\mathrm{C}$ and $\mathrm{E}$ in vitro. Environ Toxicol 26: 287-291.

Akhgari M, Abdollahi M, Kebryaeezadeh A, Hosseini R, Sabzevari O (2003) Biochemical evidence for free radical-induced lipid peroxidation as a mechanism for subchronic toxicity of malathion in blood and liver of rats. Hum Exp Toxicol 22: 205-211.

Aktar MW, Sengupta D, Chowdhury A (2009) Impact of pesticides use in agriculture: their benefits and hazards. Interdiscip Toxicol 2: 1-12.

Albesa I, Becerra MC, Battan PC, Paez PL (2004) Oxidative stress involved in the antibacterial action of different antibiotics. Biochem Biophys Res Commun 317: 605-609.

Anzenbacher P, Anzenbacherova E (2001) Cytochromes P450 and metabolism of xenobiotics. Cell Mol Life Sci 58: 737-747.

Astiz M, de Alaniz MJ, Marra CA (2009) Antioxidant defense system in rats simultaneously intoxicated with agrochemicals. Environ Toxicol Pharmacol 28: 465-473.

Bando I, Reus MI, Andres D, Cascales M (2005) Endogenous antioxidant defence system in rat liver following mercury chloride oral intoxication. $\mathrm{J}$ Biochem Mol Toxicol 19: 154-161.

Barski D, Spodniewska A (2012) Activity of selected antioxidative enzymes in rats exposed to dimethoate and pyrantel tartrate. Pol J Vet Sci 15: 239-245.

Bebe FN, Panemangalore M (2003) Exposure to low doses of endosulfan and chlorpyrifos modifies endogenous antioxidants in tissues of rats. J Environ Sci Health B 38: 349-363.

Becerra MC, Sarmiento M, Paez PL, Arguello G, Albesa I (2004) Light effect and reactive oxygen species in the action of ciprofloxacin on Staphylococcus aureus. J Photochem Photobiol B 76: 13-18.

Ben Amara I, Sefi M, Troudi A, Soudani N, Boudawara T, Zeghal N (2014) Fenthion, an organophosphorus pesticide, induces alterations in oxidant/antioxidant status and histopathological disorders in cerebrum and cerebellum of suckling rats. Indian J Biochem Biophys 51: 293-301.

Ben Amara I, Soudani N, Hakim A, Bouaziz H, Troudi A, Zeghal KM, Zeghal N (2012) Dimethoate-induced oxidative damage in erythrocytes of female adult rats: possible protective effect of vitamin $\mathrm{E}$ and selenium supplemented to diet. Toxicol Ind Health 28: 222-237.

Buyukokuroglu ME, Cemek M, Tosun M, Yurumez Y, Bas O, Yavuz Y (2008) Dandrolene may prevent organophosphate-induced oxidative stress and muscle injury. Pestic Biochem Physiol 92: 156-163.

Casida JE, Quistad GB (2004) Organophosphate toxicology: safety aspects of non-acetylcholinesterase secondary targets. Chem Res Toxicol 17: 983-998.

Cemek M, Buyukben A, Buyukokuroglu ME, Aymelek F, Tur L (2010) Protective roles of vitamin E ( $\alpha$-tocopherol), selenium and vitamin E plus selenium 
in organophosphate toxicity in vivo: a comparative study. Pest Biochem Physiol 96: 113-118.

Chow CK, Ibrahim W, Wei Z, Chan AC (1999) Vitamin $\mathrm{E}$ regulates mitochondrial hydrogen peroxide generation. Free Radic Biol Med 27: 580-587.

Defo MA, Spear PA, Couture P (2014) Consequences of metal exposure on retinoid metabolism in vertebrates: a review. Toxicol Lett 225: 1-11.

Eddleston M, Street JM, Self I, Thompson A, King T, Williams N, Naredo G, Dissanayake K, Yu LM, Worek F, John H, Smith S, Thiermann H, Harris JB, Eddie Clutton $\mathrm{R}$ (2012) A role for solvents in the toxicity of agricultural organophosphorus pesticides. Toxicology 294: 94-103.

Edge R, McGarvey DJ, Truscott TG (1997) The carotenoids as anti-oxidants - a review. J Photochem Photobiol C 41: $189-200$.

El-Demerdash FM (2011) Lipid peroxidation, oxidative stress and acetylcholinesterase in rat brain exposed to organophosphate and pyrethroid insecticides. Food Chem Toxicol 49: 1346-1352.

Fernie KJ, Shutt JL, Mayne G, Hoffman D, Letcher RJ, Drouillard KG, Ritchie IJ (2005) Exposure to polybrominated diphenyl ethers (PBDEs): changes in thyroid, vitamin A, glutathione homeostasis, and oxidative stress in American kestrels (Falco sparverius). Toxicol Sci 88: $375-383$.

Gelal A, Gumustekin M, Kalkan S, Guven H, Eminoglu O (2001) Effects of subchronic parathion exposure on cyclosporine pharmacokinetics in rats. J Toxicol Environ Health A 62: 289-294.

Giordano G, Afsharinejad Z, Guizzetti M, Vitalone A, Kavanagh TJ, Costa LG (2007) Organophosphorus insecticides chlorpyrifos and diazinon and oxidative stress in neuronal cells in a genetic model of glutathione deficiency. Toxicol Appl Pharmacol 219: 181-189.

Gotfried MH, Grossman RF (2010) Short-course fluoroquinolones in acute exacerbations of chronic bronchitis. Expert Rev Respir Med 4: 661-672.

Hallgren S, Sinjari T, Hakansson H, Darnerud PO (2001) Effects of polybrominated diphenyl ethers (PBDEs) and polychlorinated biphenyls (PCBs) on thyroid hormone and vitamin A levels in rats and mice. Arch Toxicol 75: 200-208.

Hengstermann S, Valentini L, Schaper L, Buning C, Koernicke T, Maritschnegg M, Buhner S, Tillinger W, Regano N, Guglielmi F, Winklhofer-Roob BM, Lochs H (2008) Altered status of antioxidant vitamins and fatty acids in patients with inactive inflammatory bowel disease. Clin Nutr 27: 571-578.

Hybertson BM, Gao B, Bose SK, McCord JM (2011) Oxidative stress in health and disease: the therapeutic potential of Nrf2 activation. Mol Aspects Med 32: 234-246.

Ibrahim IG, Yarsan E (2011) Enrofloxacin drug induced reactive oxygen species. ROAVS 1: 489-491.

Ihrke PJ, Papich MG, Demanuelle TC (1999) The use of fluoroquinolones in veterinary dermatology. Vet Dermatol 10: 193-204.

Irshad M, Chaudhuri PS (2002) Oxidant-antioxidant system: role and significance in human body. Indian J Exp Biol 40: 1233-1239.

Kamal-Eldin A, Appelqvist LA (1996) The chemistry and antioxidant properties of tocopherols and tocotrienols. Lipids 31: 671-701.
Kulikowska-Karpińska E, Moniuszko-Jakoniuk J (2004) The antioxidative barrier in the organism. Pol J Environ Stud 13: 5-13.

Lee SA, Belyaeva OV, Kedishvili NY (2008) Effect of lipid peroxidation products on the activity of human retinol dehydrogenase 12 (RDH12) and retinoid metabolism. Biochim Biophys Acta 1782: 421-425.

Lemus R, Abdelghani A (2000) Chlorpyrifos: an unwelcome pesticide in our homes. Rev Environ Health 15: 421-433.

Liebler DC (1993) The role of metabolism in the antioxidant function of vitamin E. Crit Rev Toxicol 23: 147-169.

Liu P, Song X, Yuan W, Wen W, Wu X, Li J, Chen X (2006) Effects of cypermethrin and methyl parathion mixtures on hormone levels and immune functions in Wistar rats. Arch Toxicol 80: 449-457.

Martinez M, McDermott P, Walker R (2006) Pharmacology of the fluoroquinolones: a perspective for the use in domestic animals. Vet J 172: 10-28.

Mutch E, Williams FM (2006) Diazinon, chlorpyrifos and parathion are metabolised by multiple cytochromes $\mathrm{P} 450$ in human liver. Toxicology 224: 22-32.

Nigg HN, Knaak JB (2000) Blood cholinesterases as human biomarkers of organophosphorus pesticide exposure. Rev Environ Contam Toxicol 163: 29-111.

Ojha A, Srivastava N (2012) Redox imbalance in rat tissues exposed with organophosphate pesticides and therapeutic potential of antioxidant vitamins. Ecotoxicol Environ Saf 75: 230-241.

Pouzaud F, Bernard-Beaubois K, Thevenin M, Warnet JM, Hayem G, Rat P (2004) In vitro discrimination of fluoroquinolones toxicity on tendon cells: involvement of oxidative stress. J Pharmacol Exp Ther 308: 394-402.

Rampal S, Kaur R, Sethi R, Singh O, Sood N (2008) Ofloxacin-associated retinopathy in rabbits: role of oxidative stress. Hum Exp Toxicol 27: 409-415.

Rodríguez-Estival J, Taggart MA, Mateo R (2011) Alterations in vitamin $\mathrm{A}$ and $\mathrm{E}$ levels in liver and testis of wild ungulates from a lead mining area. Arch Environ Contam Toxicol 60: 361-371.

Sies H (1997) Oxidative stress: oxidants and antioxidants. Exp Physiol 82: 291-295.

Sies H, Stahl W (1995) Vitamins E and C, beta-carotene, and other carotenoids as antioxidants. Am J Clin Nutr 62 (6 suppl): 1315S-1321S.

Spodniewska A, Barski D, Ziółkowski H (2014) Glutathione and glutathione-related enzymes in rats exposed to dimethoate and/or pyrantel. Pol J Vet Sci 17: 105-112.

Stahlmann R (2002) Clinical toxicological aspects of fluoroquinolones. Toxicol Lett 127: 269-277.

Suarez G, Alvarez L, Castells D, Moreno L, Fagiolino P, Lanusse C (2014) Evaluation of pharmacological interactions after administration of a levamisole, albendazole and ivermectin triple combination in lambs. Vet Parasitol 201: $110-119$.

Sultatos LG (1994) Mammalian toxicology of organophosphorus pesticides. J Toxicol Environ Health 43: 271-289.

Suojala L, Simojoki H, Mustonen K, Kaartinen L, Pyorala $\mathrm{S}$ (2010) Efficacy of enrofloxacin in the treatment of naturally occurring acute clinical Escherichia coli mastitis. J Dairy Sci 93: 1960-1969.

Suresh Babu N, Malik JK, Rao GS, Aggarwal M, Ranganathan V (2006) Effects of subchronic malathion exposure on the pharmacokinetic disposition of pefloxacin. Environ Toxicol Pharmacol 22: 167-171. 
Traber MG, Atkinson J (2007) Vitamin E, antioxidant and nothing more. Free Radic Biol Med 43: 4-15.

Tras B, Maden M, Bas AL, Elmas M, Yazar E, Civelek $T$ (2001) Investigation of biochemical and haematological side-effects of enrofloxacin in dogs. $\mathrm{J}$ Vet Med A Physiol Pathol Clin Med 48: 59-63.

Twaroski TP, O'Brien ML, Larmonier N, Glauert HP, Robertson LW (2001) Polychlorinated biphenyl-induced effects on metabolic enzymes, AP-1 binding, vitamin E, and oxidative stress in the rat liver. Toxicol Appl Pharmacol 171: 85-93.

Vancutsem PM, Babish JG, Schwark WS (1990) The fluoroquinolone antimicrobials: structure, antimicrobial activity, pharmacokinetics, clinical use in domestic animals and toxicity. Cornell Vet 80: 173-186.

Verma RS, Mehta A, Srivastava N (2007) In vivo chlorpyrifos induced oxidative stress: attenuation by antioxidant vitamins. Pest Biochem Physiol 88: 191-196.
Wang YC, Chan JP, Yeh KS, Chang CC, Hsuan SL, Hsieh YM, Chang YC, Lai TC, Lin WH, Chen TH (2010) Molecular characterization of enrofloxacin resistant $A c$ tinobacillus pleuropneumoniae isolates. Vet Microbiol 142: 309-312.

Wiaderkiewicz R, Zasadowski A, Czekaj P, Wiaderkiewicz A, Czajkowska B, Barski D, Pałasz A (2006) Effect of pyrantel and dimethoate administration on rat liver cytochrome P450 system. Bull Vet Inst Pulawy 50: 253-257.

Wielgomas B, Krechniak J (2007) Toxicokinetic interactions of $\alpha$-cypermethrin and chlorpyrifos in rats. Pol J Environ Stud 16: 267-274.

Zhang ZC, Jin FS, Liu DM, Shen ZJ, Sun YH, Guo YL (2012) Safety and efficacy of levofloxacin versus ciprofloxacin for the treatment of chronic bacterial prostatitis in Chinese patients. Asian J Androl 14: 870-874. 